\title{
Demand Side Management in China
}

\author{
Jin Zhong, Member, IEEE, Chongqing Kang, Senior Member, IEEE, and Kai Liu, Student Member,
} IEEE

\begin{abstract}
Demand side management has been one of the effective means of load shifting and peak-load shaving. In a system with distributed generations and distributed renewable energy sources, demand response can significantly improve the efficiency of electricity usage and energy saving. With the development of advance metering infrastructure, and information and communication technologies, demand side management will play an important role in smart grid. The power grid in China is highly interconnected by high voltage transmission links. The State Power Grid of China has made the strategy of developing smart grid. In this paper, we will introduce the situation of demand side management in China.
\end{abstract}

Index Terms - Demand side management, demand response, load shift, peak-load shaving, Chinese power industry.

\section{INTRODUCTION}

$\mathrm{D}$ EMAND side management (DSM) in power industry aims to reduce energy consumption and improve overall electricity usage efficiency through the implementation of policies and methods that control electricity demand. Demand side management is usually a task for power companies / utilities to reduce or remove peak load, hence defer the installations of new capacities and distribution facilities. The commonly used methods by utilities for demand side management are: combination of high efficiency generation units, peak-load shaving, load shifting, and operating practices facilitating efficient usage of electricity, etc.

With deregulation of power industry, the residential and commercial consumers also play an important role in demand side management. Especially with the recent trend of increasing penetration of distributed generations (DGs) and microgrids in distribution systems, the impacts of demand responses of end-users on peak-load shaving are significant. The latest worldwide bulk investments in smart grid technologies are started from advanced metering infrastructure (AMI) and information and communication (ICT) technologies, which will directly accelerate the implementation of demand response and improve the efficiency of demand side management.

This work was supported by the HKU Seed Funding Program for Basic Research (Project code: 200811159092), HKU Strategic Research Theme and the University Development Funding (Initiative on Clean Energy \& Environment).

J. Zhong and K. Liu are with the Department of Electrical and Electronic Engineering, the University of Hong Kong, Hong Kong (e-mail: jzhong@eee.hku.hk,kailiu@eee.hku.hk).

C. Kang is with the Department of Electrical Engineering, Tsinghua University, Beijing, China (e-mail: cqkang@tsinghua.edu.cn).
China as a developing country, the economy is growing very fast in the past decade. The electricity demand has increased significantly. The installed capacity has increased by more than $170 \mathrm{GW}(27.5 \%)$ in two year from $622 \mathrm{GW}$ (2006) to $792 \mathrm{GW}$ (2008). The fast growth of economy results in electricity shortages during 2003 to 2008 . Due to the time lag of building new power plants to serve highly increased load, demand side management becomes one of the important means of reducing peak demands and deferring new generation capacities. In this paper, we will introduce the situation of demand side management in China and its role in smart grid development.

In Section II, we will introduce the basic concepts of demand side management in power industry. In Section III, the situations of demand side management in China are introduced. Section IV discusses the issues and challenges of demand side management in China. Section $\mathrm{V}$ is the conclusions.

\section{Demand Side MANagement}

The demand side management or load management has been used as an alternative solution for system operation in past thirty years. An overall review of demand side management is provided in [1], including peak-load shaving, valley filling and load shifting. In [2], load management programs are classified as economic-based programs and stability-based programs. An economic-based program aims to minimize price spikes during peaking demand periods. A stability-based program focus on enhancing power system stability margins without installing additional facilities. In a long term, proper load management activities can reduce power system operating costs and capacity investment costs [3]. In a short term, load management can reduce customer interruption costs as well as operating costs [4].

Direct load control (DLC) is one of the commonly used tools for demand side management. The objective of DLC is to minimize uncontrollable load losses, hence lower operating cost and improve system reliability. The performance of dynamic DLC in power system operation is evaluated using Monte Carlo simulation in [5]. Unlike the price-based demand response, DLC programs are feasible with the existing metering infrastructure.

By adding economic incentives in contract with consumer, Interruptible load (IL) programs step forward on DLC and are drawing attentions as another effective mean of demand response. In the IL program, the consumers are attracted to sign a contract with ISO or utility to reduce its demand when requested, with some forms of compensation. IL is recognized 
as one of the contingency reserve services by North America Electricity Reliability council (NERC) [6]. This kind of ancillary service procured from demand side is being practicing by several utilities and markets around world. Such IL programs still need supports from mature market structure and hardware conditions.

Another commonly used tool for demand side management is price incentive program. In normal operating conditions, through price incentives, it is possible to enlarge the flexibility of demand and enhance the operation efficiency of the system. The common residential peak reduction method in the U.S. is time-of-use (TOU) tariff. TOU typically has high peak prices on weekday peaking hours and low off-peak prices for the remaining time periods. Real time pricing (RTP) follows marginal electricity market prices in real time. It provides more accurate incentives to demand response. Price-base demand response requires advanced metering infrastructure. With the development of metering technologies, critical-peak pricing (CPP) is proposed. Customers are notified of high prices in advance, then control technologies are applied to adjust load. According to the experience in California, load can be reduced significantly during critical periods [7] [8].

The major obstacle of implementing price-based load management program is the costly hardware infrastructures, such as communication, metering, and control etc. However, this problem could be resolved in the future smart grid, in which advance technologies such as two-way communication, smart metering and load control devices will be deployed for residential and commercial users as well as industrial users. There is a great potential of using demand side management to enhance customer satisfactory, system reliability and energy efficiency, while avoid unnecessary investment.

\section{Situations of Demand Side Management In ChinA}

Unlike European countries and North America, China started demand side management from 1990s. The demand side management in China is a central-controlled measure by power companies or grid companies. Nowadays, there is almost no economic-incentive based demand response in China. Demand response is encouraged especially during the electricity shortage period, 2003 to 2008 .

The power system is separated as supply side and demand side using meters as the boarder. The upstream side of the meter is supply side, and the downstream of the meter is defined as demand side.

The resources of supply sides include: all generating units, imported energy, and loss reduction (or energy saved) in the system operation.

The potential energy saving on the demand side can be implemented by

- improving the efficiency of lighting, air condition, motor, heating, etc.

- electricity storage and heat storage

- interruptible load

- energy saving methods for buildings

- adjustment of consumers' behavior, for example use electricity consumption devices during the off-peak hours

- electricity supply of distributed generations

The three major means of demand response in China are:

- $\quad$ Load shifting

Load shifting is to adjust consumers' behavior on energy consumption by using heat storage and energy storage devices, while applying peak-hour prices and interruptible load compensations.

- $\quad$ Energy saving

Encourage energy-saving bulbs, high efficiency motor, pump and transformers

- Power generation resource replacement

Encourage high efficiency energy resources

As the electricity market in China is not open on the distribution side, electricity retail prices for industrial, residential and agriculture consumers are all determined by the National Development and Reform Commission (NDRC), it is not yet possible to apply real-time pricing and interruptible load compensation in demand response program. The central-controlled demand responses are implemented by individual power companies. In this paper, we introduce the demand side managements in a few typical areas.

\section{A. Beijing}

In Beijing, the peak-hour prices, off-peak prices and seasonal prices are applied to certain large customers. In 2004, the energy consumption using peak and off-peak prices is about $63.5 \%$ of the total energy consumption. The annual load shifting due to peak and off-peak prices has reached about 200 MW. The seasonal prices adopted in recent years have effectively reduced the electricity consumption in the summer. The peak load shifted due to the seasonal prices in the summer of 2004 is $42 \mathrm{MW}$.

To enhance the effect of the central-controlled demand response program, Beijing has invested 497 energy storage (heat storage and ice storage) projects. The projects are mainly for energy storages of heat or ice during the off-peaking hours, and use the heat or ice for air conditioning during the peaking hours. The average capacity shifted by these energy storage systems is about $200 \mathrm{MW}$.

Beijing is also working on the possibility of using price incentives for demand side management. The plan is to enlarge the ratio of peak price / off-peak price to 2.9 time to 4 times. Critical time price is also proposed to increase the peaking hour prices by $10 \%$ only to the three peaking hours of every workday in July, August and September [9].

\section{B. Jiangsu province}

Jiangsu province has a large portion of industrial consumers. The province experienced serious electricity shortages in recent years. The Jiangsu Power Company invested in a project called "efficient power plant". Efficient power plant can save energy through using high efficient end user devices to avoid electricity generation, which is equivalent to a power plant. Through the "efficient power 
plant" projects, the energy saved in two years is equivalent to a 579 MW thermal power plant.

Jiangsu also implemented 233 demonstration projects of high efficiency motor, electricity storage, demand control, and energy-saving lighting, etc. The total peak load reduced due to these projects is $343 \mathrm{MW}$ [10].

\section{Guangdong province}

Guangdong province is the load center in the Southern China. The electricity shortage in 2005 can reach $5.67 \mathrm{GW}$, which is to $20 \%$ of the total demand [11] [12].

Three cities, Guangzhou, Foshan and Zhongshan, have constructed the demand side management systems. The controllable load has reached the $60 \%$ of the total load.

Since April of 2005, Guangdong applied the new peak and off-peak pricing mechanisms. The new ratio is $1.58: 1: 0.5$. This means the peak hour price is $158 \%$ of the flatten price, and the off-peak hour price is $50 \%$ of the flatten price. The peak hour price is 3.16 times of off-peak hour price. Before 2005 , the ratio is 2.25 times. The new pricing strategy is effective to demand response.

In Shenzhen, the Shenzhen power company provides electricity price promotion to commercial and industrial customers. For those companies whose working hours are moved one-hour or two-hour ahead, the electricity prices to them are reduced by CNY 0.0456 and CNY 0.1386, respectively. These are about $10-20 \%$ of regular electricity prices. For those industrial consumers, the night electricity prices could be reduced by CNY0.254 (about 50\%).

\section{Challenges}

Due to the fast growth of economy, electricity shortage is one of the emerging issues in China's development. Demand side management is a promising method to solve this problem before new capacities are installed. However, the effect and efficiency of demand response is facing two challenges: deregulation of distribution market, and the smart metering infrastructures.

Although the central controlled demand side responses can reduce peak loads and shift loads to off-peak periods to certain degrees, the large amount of incentive based demand response by end users could flatten the load curve much significantly. The effects on deferment of distribution facilities are even better. The current pricing mechanisms and the regulated distribution systems are the major obstacles to implement demand response in a wide range.

The other obstacle is the technology limitation. Nowadays, most of the end users, including most industrial consumers, are installed with the traditional metering systems. The Automatic Meter Reading (AMR) systems are only available in few systems. The Advanced Metering Infrastructure (AMI) with two-way communications has not been installed in most systems. The existing metering system is hard to support demand responses from end users.

Unlike the western countries, China has been focused on constructions of long distance high voltage transmission lines.
The investment in distribution systems and distributed generations is relatively small compare to the investment in transmission systems. The distribution networks in China are not as robust as in western countries. Most blackouts are caused by problems in the distribution systems. Compare with the developed countries, the portion of distributed generations and microgrids are very small in China. Limited number of distributed generations lowers the ability and effectiveness of demand response.

\section{CONCLUSIONS}

Under the recent trends of developing smart grids and smart metering systems, demand side management issue has been raised again as one of the important methods of energy saving. The new technologies enhance the measures of demand responses; hence improve the effectiveness of demand side management.

In this paper, we introduced the basic methods for traditional demand side management. Then we introduced the situations of demand side management in China. Apparently, the demand side management is still in old fashion and under the central control in China. The exiting DSM projects in some regions of China are presented. From the situation, we can see that there is a big potential of improving the efficiency of demand response in China. The challenges are from both policy and technique sides. The deregulated real-time retail pricing mechanisms advanced metering infrastructures and large amount of distributed generations and microgrids would facilitate the implementation of demand response and improve the efficiency of demand side management.

\section{REFERENCES}

[1] R. M. Delgado, "Demand-side management alternatives," Proceedings of the IEEE, vol. 73, pp. 1471-1488, 1985.

[2] P. Jazayeri, A. Schellenberg, W. D. Rosehart, J. Doudna, S. Widergren, D. Lawrence, J. Mickey, and S. Jones, "A survey of load control programs for price and system stability," Power Systems, IEEE Transactions on, vol. 20, pp. 1504-1509, 2005.

[3] M. D. Nelson, "Load management from a power system operator's perspective," Power Apparatus and Systems, IEEE Transactions on, vol. PAS-104, pp. 373-380, 1985.

[4] M. Fotuhi-Firuzabad and R. Billinton, "Impact of load management on composite system reliability evaluation short-term operating benefits," Power Systems, IEEE Transactions on, vol. 15, pp. 858-864, 2000.

[5] H. Salehfar and A. D. Patton, "A production costing methodology for evaluation of direct load control," Power Systems, IEEE Transactions on, vol. 6, pp. 278-284, 1991.

[6] "Operating Policy-10 on Interconnected Operations Serices," North American electric Reliability Council (NERC), Draft-3.1, 2000.

[7] S. Borenstein, M, Jaske and A.Rosenfld, Dynamic pricing, Advanced Metering and Demand Response in Electricity Markets, [on line] available: http://repositories.cdlib.org/ucei/csem/CSEMWP-105/.

[8] K. Herter, "Residential implementation of critical-peak pricing of electricity ", Energy Policy, Vol. 35, 2007, pp. 2121-2130.

[9] Zhaoguang Hu, Tiecheng Chen, Hong Ji, and Lei Zhao, "Economic analysis of implementing demand side management in Beijing", Automation of Electric Power Systems, Vol. 23, No. 13, 1999, pp. 22-25.

[10] Jiping Liu, Yihui Chen, and Jun Chen, "Efficient utilization of demand side management for power grid security and economic operation", Power Demand Side Management, Vol. 5, No. 3, 2003, pp 5-6.

[11] Weibing Sun, Yidan Liu, Min Wu, Hongshen Song, and Yang Li, "ASP and SQL technologies based DSM project management system", Electric Power Automation Equipment, Vol. 24, No. 3, 2004, pp. $22-25$. 
[12] Wei Yang, Yalin Liu, Junfang Zhang, and Junji Wu, "RTU based demand side management service system design", Power Demand Side Management, Vol. 6, No. 1, 2004, pp. 40-43.

\section{BIOGRAPHIES}

Jin Zhong (S'00, M'04) received the B.Sc. degree from Tsinghua University, Beijing, China, in 1995, the M.Sc. degree from China Electric Power Research Institute, Beijing, in 1998, and the Ph.D degree from Chalmers University of Technology, Gothenburg, Sweden, in 2003. At present, she is an Assistant Professor in the Department of Electrical and Electronic Engineering of the University of Hong Kong. Her areas of interest are smart grid, micro grid, electricity sector deregulation, ancillary service pricing, and power system planning.

Chongqing Kang (M'01, SM'07) received his Ph.D. degree from Dept. of Electrical Engineering in Tsinghua University, 1997. He is now a Professor at the same University. His research interests include low-carbon electricity, power system planning, power market, power system reliability, power system load forecasting.

Kai Liu (S'06) received the B.Sc. degree from Tsinghua University, Beijing, China, in 2005 and the MPhil degree from the University of Hong Kong, Hong Kong, in 2007, both in electrical engineering. Currently he is pursuing the Ph.D degree in the University of Hong Kong. His research topic is power system planning, and smart grid. 